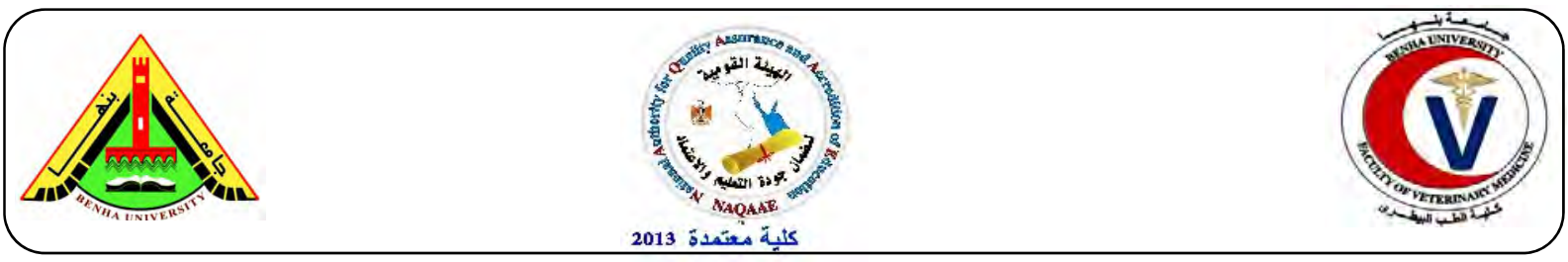

\title{
Biochemical effect of toxoplasma infestation on hormones and iron in aborted women
}

\author{
Omima, Rageb, Abd El-Maksoud, H.A., Afaf, D.A., Fathy, K.A. \\ Department of Biochemistry, Fac. of Vet. Med., Benha Univ., Egypt.
}

\begin{abstract}
A B S T R A C T
This study was performed to investigate the effect of toxoplasmosis on several biochemical parameters in aborted women (aborted due to toxoplasma) 43 women were classified into four groups. The first group contains 10 women with full term of pregnancy and normal delivers kept as control group. The second group composed of 16 women aborted one time the third group contain 10 women aborted for two time. Fourth group contain 7 women aborted for three time. Blood sample were collected from all women. The obtained result reveled that a significant increase of serum toxoplasma IgG, IgM and cortisol, on aborted groups (G2, G3 and G4) compared with control group (G1). While, there was none significance difference in cancer antigen 125 (CA125) in serum compared with control group. Also, Results showed a significant increase of immunoglobulin IgG, IgE, IgA, IL2 and IL6 and on aborted groups (G2, G3 and G4) compared with control group (G1). While, there was no significant difference of IgM between in group G4 compared with control group (G1).
\end{abstract}

Keywords: Toxoplasma, Hormones, Aborted Women, Iron.

(http://www.bvmj.bu.edu.eg)

(BVMJ-28(1): 120-124, 2015)

\section{INTRODUCTION}

The influence of sex-and pregnancyassociated hormones on the severity of $T$. gondii infection is of particular public health interest due to the ability of the parasite to cause congenital disease if infection occurs during pregnancy (Roberts et al., 2001).

Toxoplasma may infect the maternal side of the placenta in the course of acute primary disease, and if the parasite penetrates to the fetal side, the fetus may become infected. The ability of the parasite to cross the placenta depends on the anatomic characteristics of the placenta, which change with the stage of gestation. Total maternal-fetal transmission is about 30\% throughout all of gestation, but varies from $6 \%$, at 13 weeks, to $72 \%$, at 36 weeks (Dunn et al., 1999). However, fetuses were infected in early pregnancy are at a higher risk of manifesting severe clinical signs of infection (Tenter et al., 2000). The incidence of acquired primary $T$. gondii infection during pregnancy varies greatly from country to country and ranges from less than 1 to more than 15 per 1000 pregnancies (Remington et al., 1995). However, other studies showed much higher prevalence. In Egypt, El-Nawawy et al. (1996) found that the rate of acute maternal infection in susceptible pregnancies was $4 \%$ and the maternal fetal transmission rate was estimated to be $33 \%$. However, Hussein et al. (2001) reported that the risk of materno-fetal transmission was very high (50\%).

However, transplacental transmission of toxoplasma from an infected pregnant woman 
to the fetus results in fetal damage to a degree depending on the gestational age at the time of infection (Kopecky et al., 2001 and Fatoohi et al., 2002). It may lead to miscarriage, stillbirth, or congenital defects (Pinard et al., 2003).

Several studies have suggested the role of $T$. gondii infection in abortion. Sahwi et al. (1995) found that toxoplasmosis has a significant relation to abortion in the first trimester.

Regan et al. (1990) report the risk of miscarriage is $43 \%$ in patients with past history of three or more miscarriages and the risk is $28 \%$ in those with history of two miscarriages and $20 \%$ in those with history of one previous miscarriage and is only $5 \%$ in primigrvidae.

The frequency of clinically recognized abortion increases from $12 \%$ in women less than age 20 , to 26 percent in those with age 40 . For the same paternal ages the increase is from 12 to 20 percent. Finally the incidence of abortion is increased if a woman conceives within 3 months of a term birth. More than 80 percent of abortions occur in the first 12 weeks and the rate decreases rapidly thereafter (Antoniou et al., 2004).

Knudsen et al. (1991) reviewed the data for all patients admitted to hospitals in Denmark between 1980 and 1984. The overall incidence of abortion was $11.3 \%$, but the abortion risk increased steadily with the number of prior abortions. The risk of abortion in women with one prior abortion was $13 \%$, with two prior abortions it was $25 \%$, with three it was $45 \%$, and with four prior abortions the risk of abortion was $54 \%$.

Kutteh and Pasquarette (1995) found that couples with a history of previous reproductive success plus miscarriages have an approximately $70 \%$ chance of producing a live-born in any subsequent pregnancies, however, couples with no live-born offspring have an overall lower success rate of about
$50 \%$. The main objective of this work was to indicate the effect of Toxoplasma on female sexual hormones and iron in aborted womens.

\section{MATERIAL AND METHODS}

\subsection{Patients:}

The study population comprised 43 women, with age range between 20 and 40 years, They came to Gynecological and Family Planning Departments in Samalot General Hospital in El-Minya Governorate for follow up them pregnancy. Among the study population, four groups were defined according to the obstetric history of pregnancy:

Group I: (Control healthy group) $(n=10)$ the group with clinical data suggestive of negative Toxoplasma infection. These cases presented: 10 cases of full term off pregnancy and normal delivery.

Group II: (First abortion) $(\mathrm{n}=16)$ the group with clinical data suggestive of Toxoplasma infection. These cases presented: 16 cases of abortion for first time.

Group III: (Second abortion) $(\mathrm{n}=10)$ the group with clinical data suggestive of Toxoplasma infection. These cases presented: 10 cases of abortion for second time:

Group IV: (Third abortion) $(n=7)$ the group with clinical data suggestive of Toxoplasma infection. These cases presented: 7 cases of abortion for third time:

\subsection{Blood sample and biochemical analysis:}

\subsubsection{Collection of sample:}

Peripheral blood samples of all parturient women and aborted women were collected. The collected sample was transferred to $5 \mathrm{ml}$ vacutainer tubes, left to stand about 30 minutes in room temperature, then centrifuged ( 5 minutes, 3000 r.p.m) and all available sera were stored at $-20^{\circ} \mathrm{C}$, vials, until being analysis.

\subsubsection{Biochemical tests:}


Effect of toxoplasma infestation on immunity and inflammatory markers in aborted women

o Serum prolactin was determined by method described by Bayoumi et al. (2009).

o Serum progesterone and estrogen concentration was determined by enzyme immunoassay test according to the method described by Radwanska et al. (1978).

o Iron was determined according to the methods described, Patterson et al. (2001).

\subsection{Statical analysis}

The Statistical analysis was carried out using ANOVA with two factors under significance level of 0.05 for the whole results using SPSS (ver. 19). Data were treated as complete randomization design according to Steel et al.
(1997). Multiple comparisons were carried out applying LSD.

\section{RESULTS}

The present data in Table (1) and illustrated in Figure (1) showed that a significant decrease of serum progesterone, estrogen hormones and iron in aborted group on compared to control group. While there is a significant increase of serum prolactin hormone in aborted group on compared with control group. Progesterone, estrogen hormones and iron were decreased with increasing of number abortion. While, prolactin hormone was increased with increasing of number abortion.

Table 1: Effect of toxoplasma on progesterone, estrogen, prolactin and iron.

\begin{tabular}{lcccc}
\hline \multirow{2}{*}{ Parameter } & \multicolumn{4}{c}{ Group } \\
\cline { 2 - 5 } & $\begin{array}{c}\text { G1 } \\
\text { (control) }\end{array}$ & $\begin{array}{c}\text { G2 } \\
\text { abortion) }\end{array}$ & $\begin{array}{c}\text { G3 } \\
\text { (Second } \\
\text { abortion) }\end{array}$ & $\begin{array}{c}\text { G4 } \\
\text { (Third abortion) }\end{array}$ \\
\hline $\begin{array}{l}\text { Progsterone } \\
\text { (ng/ml) }\end{array}$ & $4.15 \pm 0.31^{\mathrm{d}}$ & $3.1 \pm 1.92^{\mathrm{c}}$ & $2.18 \pm 2.11^{\mathrm{b}}$ & $1.75 \pm 2.09^{\mathrm{a}}$ \\
Estrogen (Pg/ml) & $139.81 \pm 2.35^{\mathrm{d}}$ & 101.57 & & \\
Prolactin (ng/ml) & $8.17 \pm 0.72^{\mathrm{a}}$ & $16.75 \pm 2.70^{\mathrm{b}}$ & $15.31 \pm 2.15^{\mathrm{b}}$ & $27.81 \pm 3.98^{\mathrm{c}}$ \\
Fe (mg/dL ) & $1.39 \pm 0.05^{\mathrm{b}}$ & $0.81 \pm 0.11^{\mathrm{a}}$ & $0.56 \pm 0.27^{\mathrm{a}}$ & $0.41 \pm 0.30^{\mathrm{a}}$ \\
\hline
\end{tabular}

$\mathrm{a}, \mathrm{b} \& \mathrm{c}$ : There is no significant difference $(P>0.05)$ between any two means, within the same row have the same superscript letter. 


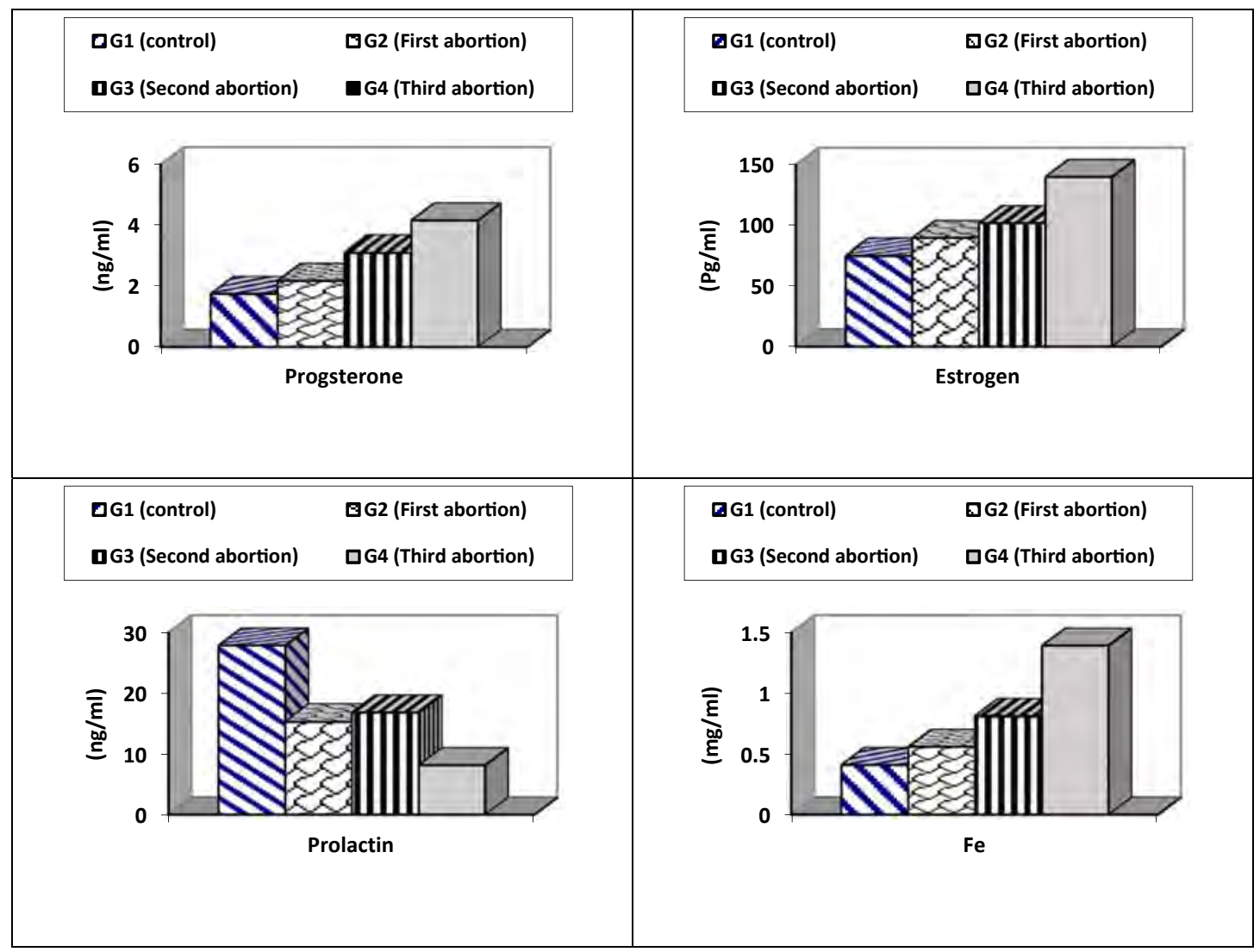

Fig. (1): Effect of toxoplasma on progestron, estrogen, prolactin and iron

\section{DISCUSSION}

The present data revealed a significant increase in prolactin, while a significant decrease in serum progestron, estrogen and iron. These results may explain why toxoplasmosis was more prevalent in pregnant women who can be through a fact that sharp elevated progesterone and estradiol levels in pregnant females improve susceptibility to T. gondii, mainly through suppressing host immune endocrine network (IEN) and progressing parasite re-conversion and latency. Also, the higher incidence of Toxoplasma encephalitis was recorded within AIDS-defining females than in males and this support that female hormones possibly predispose to latent toxoplasmosis (Roberts, C.W. et al., 2001)
Where PRL levels are high. The following works described some PRL actions on inflammatory or innate immune response to several protozoa (Benedetto and Auriault, 2002).

It was found that there is an alteration in the trace elements concentrations levels, such as $\mathrm{Zn}, \mathrm{Cu} \cdot \mathrm{Mg}$ and $\mathrm{Fe}$, associated with some human diseases. However, our results show that toxoplasmosis somehow led to decreased Fe levels in sera. This is the first study that gives a clear indication of the relationship between toxoplasmosis and deficiency in iron among all trace elements. It has been reported that iron deficiency affects $20-50 \%$ of the world's population. Therefore, it represents the most common trace element deficiency worldwide (Patterson et al., 2001). In conclusion an association between female 
sexual hormone, iron and abortion caused by toxoplasma in women. There is increase in serum prolactin and decrease in serum progesterone, estrogen, iron. We recommend

\section{REFERENCES}

Antoniou, M., Tzouvalia, H., Sifakisb, S., Galanakisd, E., Georgopouloua, E., Liakouc, V., Koumantakisb, E., Tselentisa, Y. 2004. Incidence of toxoplasmosis in 5532 pregnant women in Crete, Greece: management of 185 cases at risk. Eur. J. Obstet. Gynecol. Reprod. Biol., 117(2): 138-143.

Bayoumi, N.K., Elhassan, E.M., Elbashir, M.I., Adam, I. 2009. Cortisol, prolactin, cytokines and the susceptibility of pregnant Sudanese women to Plasmodium falciparum malaria. Ann Trop Med Parasitol, 103: 111-7.

Benedetto, N., Auriault, C. 2002. Prolactincytokine network in the defence against Acanthamoeba castellanii in murine microglia [corrected.[ Eur Cytokine Netw, 13: 447-55.

Cunningham, F., Gant, N., Leveno, K., Gilstrap, L., Haut, J., Wenstrom, K. Aborion. In: Cunningham, F., Gant, N., leveno, K., Gilstrap, L., Haut, J. and Wenstrom, K. 2001. Williams Obsterics, pregnant women should be taken antitoxoplasma drags. Whatever they are positive or negative toxoplasmaic.

21st Edition, Prentice-Hall International Inc., 855: 882.

Patterson, A.J., Brown, W.J., Roberts, D.C.K. 2001. Dietary and Supplement Treatment of Iron Deficiency Results in Improvements in General Health and Fatigue in Australian Women of Childbearing Age. $\mathrm{J}$ the American College of Nutrition 20: 337-342.

Radwanska, E., Frankenberg, J., Allen, E. 1978. : Plasma progesterone levels in normal and abnormal early human pregnancy. Fertility and Sterility, 30: 398-402.

Regan, L., Owen, E.J., Jacobs, H.S. 1990. Hypersecretion of luteinizing hormone, infertility and miscarriage. Lancet, II: 114-141.

Roberts, C.W., Walker, W., Alexander, J. 2001. Sex-associated hormones and immunity to protozoan parasites. Clin. Microbiol. Rev., 14: 476-488.

Styrt, B., Sugarman, B. 1990. Estrogens and infection. Rev. Infect. Dise., 13: 11391184. 